\title{
Ferdighetssenteret ved Det medisinske fakultet, Universitetet i Oslo
}

\author{
Ferdighetssenteret ved Det medisinske fakultet, Universitetet i Oslo \\ ble opprettet på nye Rikshospitalet i 2001. Det startet i det små med \\ innkjøp av øvingsmodeller og produksjon av multimediaprogrammer \\ på PC med bruk av lyd, tekst, bilder, animasjoner og video for å illu- \\ strere praktiske prosedyrer. Senteret har etter dette utviklet seg til \\ å bli en viktig bidragsyter til aktiv innlæring av praktiske medisinske \\ prosedyrer for medisinstudenter.
}

\section{Bjarte Larsen}

bjartelars@hotmail.com Byfogd Rønnebergsvei 15 6008 Ålesund

\section{Hanne Storm}

Ferdighetssenteret

Det medisinske fakultet

Universitetet i Oslo

Modellen er hentet fra Universitetet i Maastricht (1) og ble lansert med den nye studieplanen i 1996, Oslo-96 (2). Senteret er presentert også tidligere i Tidsskriftet (3-5), og vi ønsker nå å gi en oppdatering over hva som er skjedd de senere årene.

Senteret består i dag av seks undersøkelsesrom med tilhørende utstyr og PC (tab 1). Studentenes identitetskort virker som nøkkel slik at de kan bruke senteret døgnet rundt. Alle rommene inneholder plansjer over relevant anatomi og medisinske prose- dyrer. For å trene på de forskjellige ferdighetene er det laget instruksjonsmanualer på hvert rom. Til de fleste av de kliniske ferdighetene det kan trenes på, hører det til multimediaprogrammer som er fritt tilgjengelig via senterets hjemmeside.

\section{Formålet med senteret}

Målsettingen og formålet med Ferdighetssenteret er å gjøre medisinstudentene tryggere på å utføre kliniske ferdigheter gjennom å gi dem kunnskap om og anledning til å trene på ferdighetene på modeller og på hverandre. Senteret ønsker å være en hjelpeinstitusjon for studentene i arbeidet med å tilegne seg de ulike ferdighetene som er definert i studieplanen. Målet er å nå frem til alle medisinstudentene, fra tidlig i studiet. Vi har sett at få studenter har benyttet seg av senteret på egen hånd, og vi har derfor prøvd å utvikle oss til å bli en mer aktiv

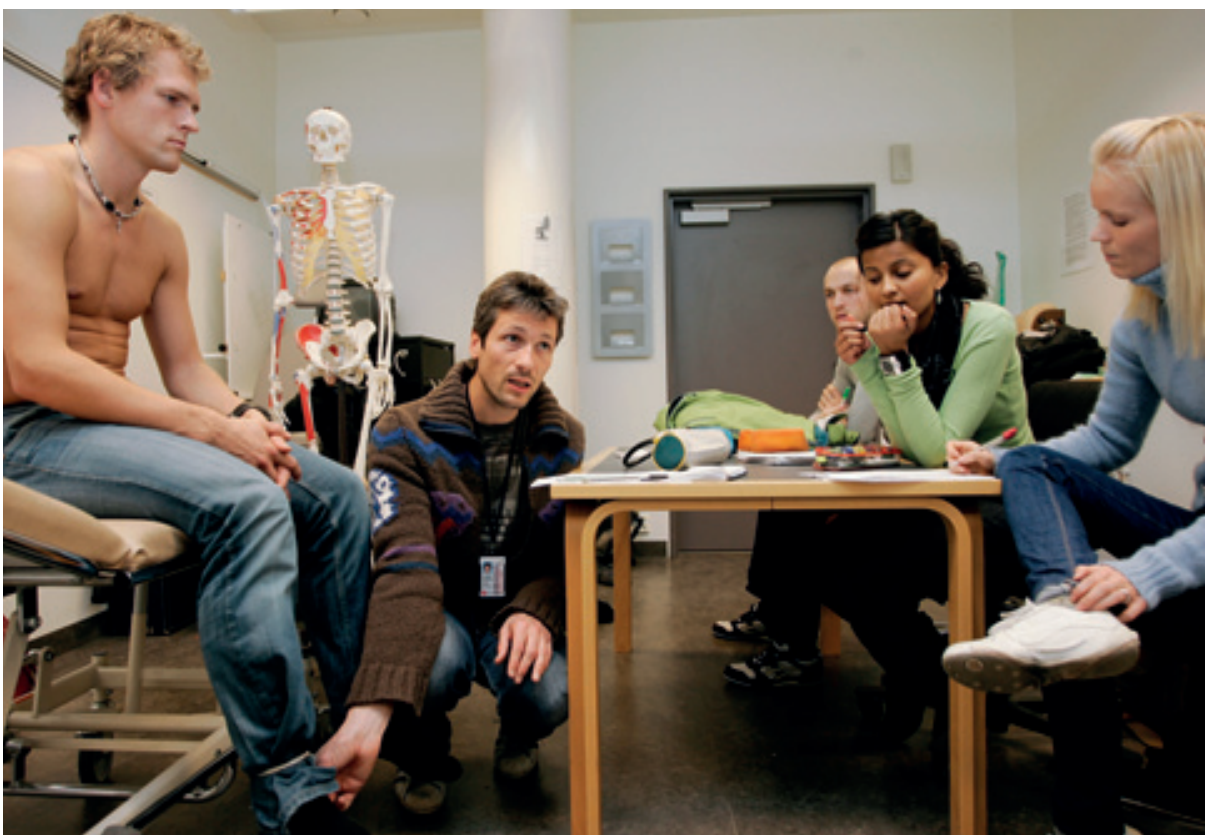

Studentene blir vist praktisk undersøkelsesteknikk. Begge foto Audun Halaas

øvelsesinstitusjon for kliniske ferdigheter. I de siste årene har opplegget vært basert mer på aktiv kursing i ferdighetsstrening, heller enn at studentene skulle komme og trene ferdigheter på eget initiativ.

\section{Ressurser}

Senteret har for tiden ti ansatte, hvorav én førsteamanuensis/lege i $55 \%$ stilling som leder ved senteret og $45 \%$ av stillingen dedikert til forskning. Det er ni medisinstudenter ansatt som vitenskapelige assistenter, hver i $21,33 \%$ stilling. Studentinstruktørene legger til rette for kurs mellom egne forelesninger og på kveldstid. Studentene ansettes for ett år om gangen fra og med tredje semester. Instruktørene slutter når studiet er over. Årlige driftsmidler er på kr 250 000. Lønnsmidlene utbetales gjennom universitetsadministrasjonen, som også bidrar til praktiske oppgaver, som å avtale møtetider for mødre med barn til kurs i pediatrisk undersøkelse.

\section{Endringer de siste årene \\ Markedsføring}

For å øke oppmerksomheten om senteret har vi arrangert åpen dag én gang $i$ året hvor nye studenter på første og andre semester kan bli kjent med senteret og dets tilbud. Vi har også gjennomført en spørreundersøkelse blant studentene der de kunne rangere de kursene de aller helst ønsket seg. På bakgrunn av resultatene er det opprettet nye frivillige kursrekker, som undersøkelse av bevegelsesapparatet, kurs i EKG-taking og -tyding, hjertelunge-redning, gynekologisk undersøkelse, undersøkelse av spedbarn og spinalpunksjon. Fakultetets semesterplan er veiledende for hvilke ferdigheter studentene skal oppnå i løpet av studiet og som Ferdighetssenteret kan bidra til ved nye kurs.

\section{IT}

Vi har også satt søkelyset på bedring av e-læringsressursene/webprogrammer ved å ansette studentinstruktører med IT-kunnskap. Siktemålet har vært omlegging og fornying av våre hjemmesider tilpasset universitetssystemet. Påmelding til kursene foregår nå elektronisk. Som en del av studentprosjekter er det også laget en utlånsvideo av undersøkelse av nyfødte og ettåringer, og multimediaprogram i pediatri. Video og multimediaprogram er utviklet som bakgrunnsinformasjon til kursene som holdes i pediatrisk undersøkelsesteknikk ved senteret. 


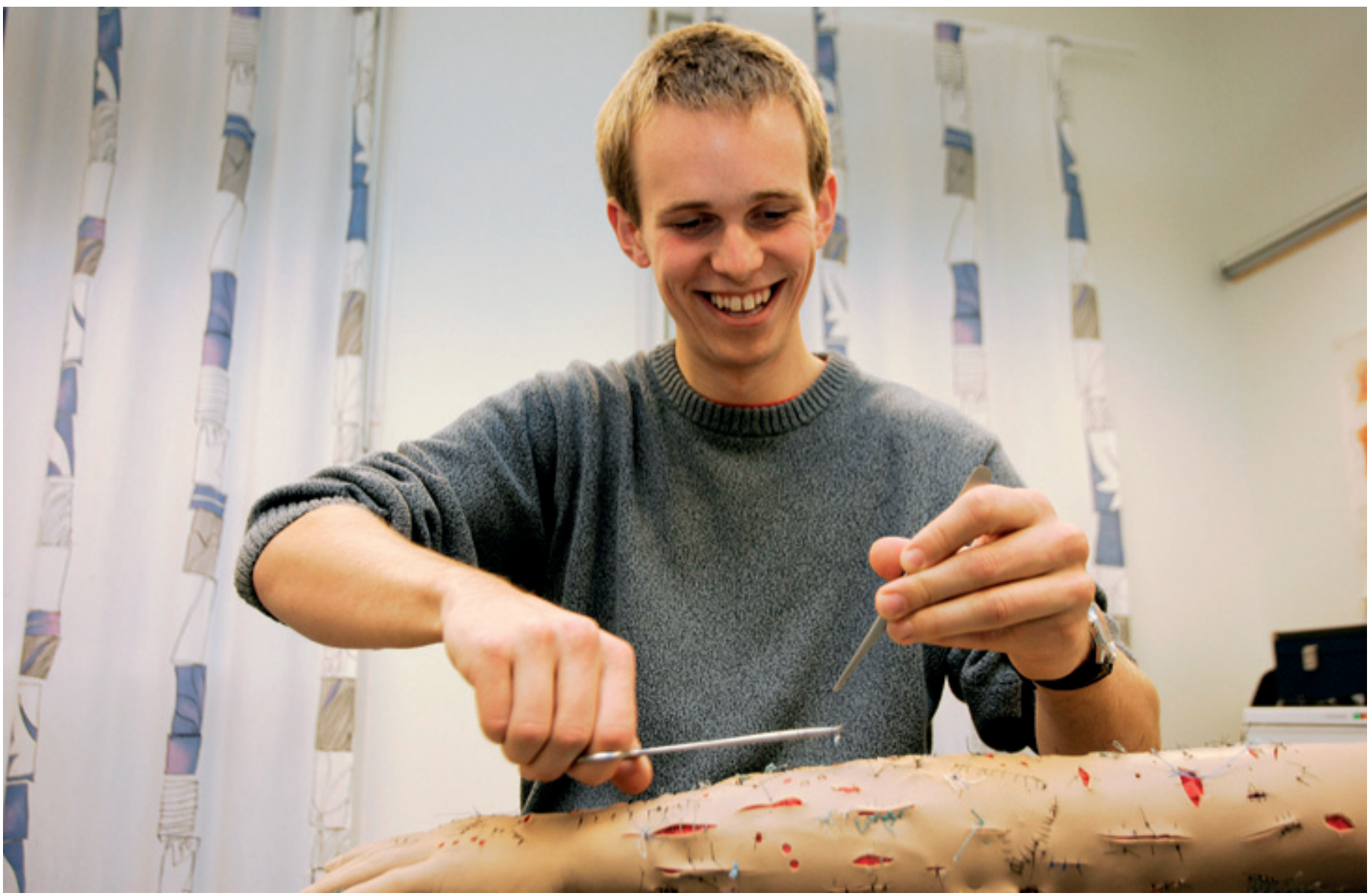

Det øves også på suturteknikk ved Ferdighetssenteret ved Det medisinske fakultet, Universitetet i Oslo

\section{Kvalitetssikring}

Det er opprettet en ferdighetsbank som inneholder kursmanualer og nettbaserte kvalitetstestede studieressurser, med link fra hjemmesidene våre. Ferdighetsbanken sikrer at nye instruktører lett kan overta ansvaret for de ulike kursene ved å hente ut materiale fra banken til gjennomføringen av kursene. For å unngå utstyrsmangler på rommene, har Ferdighetssenteret romansvarlige instruktører med ansvar for hvert sitt rom, i tillegg til at senteret har ukentlige ryddevakter for å sørge for at det er orden i utstyret på de ulike rommene. Kvalitetssikring av kursene skjer ved at kliniske stipendiater eller andre universitetsansatte på det aktuelle fagområdet går gjennom undervisningen med instruktørene. Dette gjøres primært en gang hvert semester, i forkant av start på de ulike kursene. Alle studentinstruktørene, uansett fagfelt de underviser $\mathrm{i}$, kan delta på denne kvalitetssikringen som et internt faglig forum for diskusjon. Til undervisningen i hjerte-lunge-redning er alle instruktørene sertifiserte HLR-instruktører. Vi har også lagt vekt på evaluering av alle kursene vi holder.

\section{Utstyr}

Ferdighetssenteret har som mål å være oppdatert på nytt øvingsmateriale og har kjøpt inn nye modeller og annet utstyr, blant annet to nye EKG-maskiner, rektaleksplorasjonsmodeller og gynekologiske modeller.

\section{Ferdighetssenteret i dag}

Senteret holder nå to obligatoriske kurs og sju frivillige for studentene ( $\operatorname{tab} 2$, tab 3 ). Totalt undervises nærmere 1000 deltakere fordelt på 183 kurs hvert semester. Vi har i dag ansvar for en del av den obligatoriske propedeutikkundervisningen i tredje og fjerde semester. Studentinstruktørene underviser her i undersøkelse av hals/ thorax/sirkulasjon, og undersøkelse av abdomen og rektaleksplorasjon. Dette er obligatorisk for studentene.

I siste halvdel av fjerde semester har medisinstudentene undervisning i bevegelsesapparatet. Da tilbyr vi to ulike frivillige kurs, ett i undersøkelse av overekstremi-

Tabell 1 Ferdighetssenterets ulike rom

\begin{tabular}{|ll}
\hline Rom & Utstyr \\
\hline Hjerte-lunge-rom & $\begin{array}{l}\text { Hjerte-lunge-redning på voksne og barn. Intubering på } \\
\text { dukke. Taking av EKG/blodtrykk. Digitalt fellesstetoskop }\end{array}$ \\
\hline Infusjons-/suturrom & $\begin{array}{l}\text { Kateterisering, infusjon og suturering. Biopsier på arm- } \\
\text { modeller, innleggelse av kateter på bekkenmodeller mann } \\
\text { og kvinne. } \\
\text { Utstyr for blodprøvetaking }\end{array}$ \\
\hline Gynekologi og obstetrikk & $\begin{array}{l}\text { Modell for palpasjon av mammae med tumor. Gravida- } \\
\text { modell for Leopolds håndgrep og fosterlyd. Modeller for } \\
\text { gynekologisk undersøkelse med utstyr til prøvetaking }\end{array}$ \\
\hline Øre-nese-hals, øye og nevrologi & $\begin{array}{l}\text { Modeller for spinalpunksjon, oftalmoskopi og otoskopi } \\
\text { med ulike patologiske funn. Tonometri og audiometri. } \\
\text { Brillekasse }\end{array}$ \\
\hline Thorax, abdomen og mikroskopi & $\begin{array}{l}\text { Fellesmikroskop. Modeller for rektaleksplorasjon med } \\
\text { prostatapatologiske funn. Anorektoskop }\end{array}$ \\
\hline Pediatri og kommunikasjon & $\begin{array}{l}\text { Utstyr for pediatrisk undersøkelse. } \\
\text { Mulighet for trening i kommunikasjon, todelt rom med } \\
\text { enveisvindu med høyttalerforbindelse mellom rommene }\end{array}$ \\
\hline
\end{tabular}




\begin{tabular}{|lccccc|}
\hline Tabell 2 Obligatoriske kurs & \multicolumn{1}{c}{ Timer } \\
per kurs & $\begin{array}{c}\text { Antall } \\
\text { kurs }\end{array}$ & $\begin{array}{c}\text { Totalt } \\
\text { antall timer }\end{array}$ & $\begin{array}{c}\text { Deltakere } \\
\text { per kurs }\end{array}$ & $\begin{array}{c}\text { Deltakere } \\
\text { totalt }\end{array}$ \\
\hline Kurs & 2,5 & 19 & 47,5 & $7-8$ & $133-152$ \\
\hline 3. semester propedeutikk & 2,5 & 14 & 35 & $7-8$ & $98-112$ \\
\hline 4. semester propedeutikk & - & 33 & 82,5 & - & $231-264$ \\
\hline Totalt & & & & &
\end{tabular}

\begin{tabular}{|lccccc|}
\hline Tabell 3 Frivillige kurs & $\begin{array}{c}\text { Timer } \\
\text { per kurs }\end{array}$ & $\begin{array}{c}\text { Antall } \\
\text { kurs }\end{array}$ & $\begin{array}{c}\text { Totalt } \\
\text { antall timer }\end{array}$ & $\begin{array}{c}\text { Deltakere } \\
\text { per kurs }\end{array}$ & $\begin{array}{c}\text { Deltakere } \\
\text { totalt }\end{array}$ \\
\hline Kurs & 2,5 & 16 & 40 & $10-12$ & $160-192$ \\
\hline 4. semester bevegelsesapparat & 2 & 10 & 20 & $8-10$ & $80-100$ \\
\hline 5. semester EKG & 1,5 & 10 & 15 & $8-10$ & $80-100$ \\
\hline 7. semester spinalpunksjon & 1,5 & 10 & 15 & $8-10$ & $80-100$ \\
\hline 9. semester gynekologi & 1 & 80 & 80 & 1 & 80 \\
\hline 9. semester pediatri & 1,5 & 8 & 12 & 8 & 64 \\
\hline 10. semester HLR & 2,5 & 16 & 40 & $10-12$ & $160-192$ \\
\hline 12. semester bevegelsesapparat & & 150 & 222 & & $704-828$
\end{tabular}

teter, rygg og nakke og ett av underekstremiteter. Det er kun tidligere utdannede fysioterapeuter, som nå studerer medisin, som underviser i disse kursene. Disse kursene holdes også for studenter i siste semester som en forberedelse til avsluttende klinisk eksamen.

For studentene i niende semester holdes det kurs i gynekologisk undersøkelse, deriblant innsetting av spiral. Det er også tilbud om kurs i pediatrisk undersøkelsesteknikk. I pediatrikurset får hver student en time til å undersøke et friskt spedbarn, med mor eller far til stede, sammen med en studentinstruktør. Barna blir «vervet» fra helsestaser ut til å fungere bra, og vi har inntrykk av at dette gir lav terskel for å spørre. Instruktørene er selv medisinstudenter og vet hvor skoen trykker. Hver enkelt instruktør får selv tilbakemelding via evalueringsskje- maene, som i tillegg gir informasjon som sikrer at undervisningen på Ferdighetssenteret er lagt på riktig nivå.

\section{Fremtiden}

Vi har hatt en stor vekst de siste årene når det gjelder antall kurs og deltakere. Med små midler er senteret blitt en viktig institusjon for ferdighetsstrening av medisinstudentene. Vi har aldri holdt flere kurs enn nå. Etterspørselen er fortsatt er stor, og studentene ønsker flere nye kurs. Tar vi utgangspunkt i studieplanen er det mange flere kurs som burde vært opprettet. Gipslegging, suturering, prøvetaking av arteriell blodgass og injeksjonsteknikker er noe av det som kreves av praktiske ferdigheter i studieplanen (6). Med utgangspunkt i nåværende økonomi og aktivitetsnivå er det ikke mulig å igangsette mer undervisning uten økte ressurser.

Oppgitte interessekonflikter: Ingen

\section{Litteratur}

1. Scherpbier A. A quality assessment of skills training. Maastricht: University Press Maastricht, 1997

2. Oslo-96: ny studieplan for legestudiet. Oslo: Det medisinske fakultet, Universitetet i Oslo, 1996.

3. Grøndalen IM, Gravning JA. Ferdighetssenteret hjelp til ansvar for egen læring. Tidsskr Nor Lægeforen 2006; 126: 2073.

4. Grøndalen IM, Gravning JA. Ferdighetstrening. Tidsskr Nor Lægeforen 2006; 126: 2116-7.

5. Sundar. Ferdighetssenteret - åpent øvingshus for medisinstudenter. Tidsskr Nor Lægeforen 2001; 121: $2323-4$

6. Oversikt over ferdigheter etter semester. Det medisinske fakultet, Universitetet i Oslo www.med.uio.no/rh/ferdighetssenteret/ ferdighetsliste.html (8.11.2008).
Manuskriptet ble mottatt 11.9. 2008 og godkjent 20.11. 2008. Medisinsk redaktør Are Brean. 